\title{
The Influence of Exerted Pressure, Awareness and Attitude on Students Use of e-Registration
}

\author{
Mmamolefe R. Kgasi and Billy M. Kalema
}

\begin{abstract}
This paper describes a model for measuring university students' acceptance and use of e-registration system by examining the influence of awareness, exerted pressure and attitude constructs together with three constructs of the Unified theory of acceptance and use of technology (UTAUT). The study is informed by data collected from Tshwane University of Technology (TUT), with a survey of 300 students sampled from four campuses. Results show that awareness, effort expectancy and social influence when mediated by behavioural intention predict actual usage whereas exerted pressure directly influences actual usage of e-registration. The study makes significant contributions to the literature of students' acceptance, adoption and use of web-based tools in the academic domain.
\end{abstract}

Index Terms-Online registration, web-based tools, e-registration, acceptance and use of technology.

\section{INTRODUCTION}

Many South African universities are in the era of post merger which has caused an exponential increase in their demographic structures and educational transformations. Thousands of students are enrolled every year and are given limited time to do registration. In an attempt to meet the registration deadlines, all students tend to register concurrently. This causes chaotic situations as the university staff becomes overwhelmed by excess workload resulting from the management of large number of students leading to inefficiency and ineffectiveness on the part of the university staff. At worst situations this may also result into strikes as students complain of poor and slow services provisioning.

As remedy to counteract these short comings, universities have deployed Enterprise Resource Planning (ERP) and standalone Management Information Systems (MIS) to facilitate these processes [1]. The e-registration system of TUT is a component of Integrated Tertiary Software (ITS), that is designed with the Student iEnabler a self-service application that allows students direct access to their information through a browser-based application. The iEnabler allows students to register at any time and place. If iEnabler is used successfully, students would be in position to make online application for studies, residences, registrations, inquiries, payments and requests for critical information. However, this system's usage for e-registration is too limited and has benifted little to the university.

Manuscript received October 1, 2014; revised March 13, 2015.

Mmamolefe R. Kgasi is with the Department of End User Computing, Tshwane University of Technology, South Africa (e-mail: kgasimr@tut.ac.za).

Billy M. Kalema is with the Department of Informatics, Tshwane University of Technology, South Africa (e-mail: kalemabm@tut.ac.za).
As [1] rightly noted, institutions of higher learning invest colossal sums of money on Information Technology (IT) infrastructure acquisition. However, much as huge sums are spent, it is argued that students may not use these systems as expected [2]. The non-usage of these systems has been attributed to various factors that influence student's acceptance and use of IT systems.

In a related study, [3] suggest that, the acquired IT systems should be effectively used within an organisation so as to realize their potential benefits. It is therefore important to have a clear level of understanding of the factors that influences students' behaviour to use IT systems a university may have invested in. This helps to avoid resistance and abandonment of the system that may lead to significant loses.

This study develops a conceptual framework that could be used by the institutions' management to support decision making when investing into IT infrastructure. This paper is expected to theoretically contribute to the literature of students' acceptance and use of web-based tools in the academic domain.

The remaining part of this paper is succinctly summarized as follows. First is the discussion of the related literature and research framework. This is followed by the description of the methodology, then the presentation of the analysis and results of the work. The last section is the conclusion of the work and future study.

\section{RELATED STUDY AND CONCEPTUAL FRAMEWORK}

Researchers [4], [5] who have studied information systems' failures and successes in organizations do agree that organizations overlook critical factors that influence system usage. Such factors could be modelled by the organizational culture and social structures, individual behaviours and perception and models of information sharing. A clear identification of these factors may offer important technology and business gains that may include:-

1) Helping developers to become aware of strong and weak points of system and ensure that the right business system is being developed.

2) Effectively reduce time, cost, energy and probability of system failure and accelerate time to market.

It is important to note that systems that are used periodically like the e-registration system differ in their initial adoption and subsequent continued usage. Researchers [6] noted that the factors that influenced the initial acceptance and use of such systems may vary when it is continued to be used. This could see students using e-registration at the beginning of the semester and most probably when they have pressure to meet deadlines. In such cases, when the pressure 
ceases many students may have little or no reasons to use the system.

As [5] noted, the post adoption experiences with technology like e-registration system may influence students' perception and attitude towards its continued usage. Unfortunately, most of the information system research focuses more on systems' adoption and acceptance rather than usage.

Researcher such as [5], [7], [8] noted that performance expectancy, effort expectancy, social influence are key factors influencing usage. However, as noted by [9] indicated that for online systems the issue of trust need to be given consideration. However, the noted that trust comes as result of awareness.

As [7] noted that continued usage may bring efficacy to use technology. This implies efficacy with technology and attitude are significant factors in explaining the way people react towards a new phenomenon [10]. It is from this psychological perspective and belief that many studies of adoption, acceptance and use of technology find their solid roots. Hence, this study tested the influence of; awareness, attitude, exerted pressure, performance expectance, effort expectance, social influence and efficacy with technology to e-registration usage.

\section{A. Explanation of Terms}

Performance Expectancy: in relation to e-registration system, performance expectancy explains the degree to which students believe that using e-registration smoothen their registration exercise [5], [7].

Effort expectancy: In this case effort expectancy may be looked at as the degree to which students perceive e-registration as easy to use [5].

Social Influence: This relates to the degree to which students believe that other important individuals want them to use e-registration [6], [7].

Attitude Construct: This may be looked at as a construct that exhibits the manner, disposition, feeling and position of an individual's degree to like or dislike a situation [11].

Awareness Construct: in relation to this study, this refers to the communication of reliable information regarding the e-registration system. Such information may include; privacy, security and performance functionalities that could help to build trust of the system.

Exerted Pressure Construct: Exerted pressure or time pressure refers to source of stress when users want to meet deadlines in accomplishing their tasks [12]. In regards to e-registration, exerted pressure refers to the degree affected by university administration to the students to register on time as they try to balance with that affected to them by their places of work or personal problems.

\section{B. Conceptual Framework}

Based on the six constructs identified, the conceptual framework was designed to examine their influence in e-registration. These constructs were mediated by efficacy with Web-based tools. The conceptual framework is as demonstrated in Fig. 1 below.

\section{Hypotheses Development}

From the constructs of the framework, eight relationships were hypothesized. These were as follows;

H1: Effort expectancy when mediated by efficacy with Web-based tools influences e-registration usage

H2: Performance expectancy when mediated by efficacy with Web-based tools influences e-registration usage

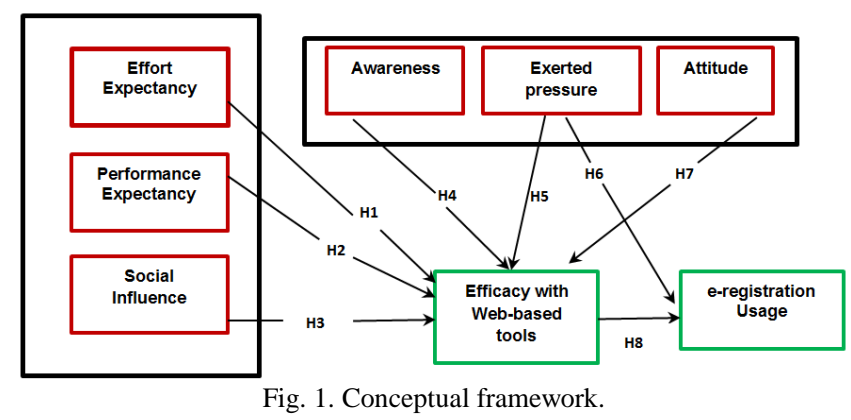

H3: Social influence when mediated by efficacy with Web-based tools influences e-registration usage

H4: Awareness when mediated by efficacy with Web-based tools influences e-registration usage

H5: Exerted pressure when mediated by efficacy with Web-based tools influences e-registration usage

H6: Exerted pressure influences e-registration usage

H7: Attitude when mediated by efficacy with Web-based tools influences e-registration usage

H8: efficacy with Web-based tools influences e-registration usage

\section{METHODOLOGY}

Based on the constructs of the framework, a closed-ended questionnaire was designed using a 5 point-Linkert scale where 5 and 1 represented strongly agree and strongly disagree respectively, 3 represented neutral whereas 4 and 2 were respective intermediate values. Four hundred (400) questionnaires were distributed to four campuses of the university; Pretoria West, Soshanguve, Ga-Rankuwa and Polokwane. Of the distributed questionnaires, 364 were returned giving a response rate of $91 \%$. The high response rate was obtained because the researchers depended on lecturers to distribute the questionnaire before or at the end of the lectures.

Three hundred and forty (340) out of the distributed 400 questionnaires were returned yielding a response rate of $85 \%$. The high response rate was obtained due to the fact that the researcher depended basically on lecturers to help distribute the questionnaire to their students after the lecture period and the responses were collected from the students in the subsequent class by the lecturers. Of the 340 returned questionnaires 300 were usable, as 40 were discarded due to incomplete responses. Data was analyzed using SPSS v21.

The overall reliability of the measuring instrument tested by Cronbach's alpha $(\alpha)$ was 0.906 . Similarly, individual constructs' reliability were also found to have reliability above the threshold a value greater than the recommend threshold of 0.70 [13].

For simplicity, the constructs were coded before data was transcribed in SPSS for analysis. Effort expectancy was coded as EE; Performance expectancy-PE; Social influence - SI; 
Awareness - AW; Exerted pressure - EP; Attitude - ATT; Efficacy with web-based tools - EWT and e-registration usage - EregUsage.

\section{ANALYSIS AND RESULTS}

Frequencies of the demographics of the participants were obtained (results left out) then the correlation and regression analysis. From the correlation analysis (Results left out due to space) it was established that exerted pressure has direct significant relationship at 0.01 level of significance with e-registration.

\section{A. Regression Analysis}

The regression analysis demonstrated in Table I was carried out to determine how each construct contribute to the overall prediction of the model. Results indicated that effort expectancy (EE), exerted pressure (EP), Awareness (AW) and Social influence (SI) significantly contribute to e-registration usage. Exerted pressure had the highest significant contribution of $28.8 \%$ at $p=0.000<0.05$, followed by Awareness with $25.9 \%$ at $p=0.022$; Effort expectance with $20.6 \%$ and Social influence (SI) with $16 \%$. On the other hand, Performance expectancy (PE), and Attitude (ATT) were found not to significantly contribute to e-registration usage. Further still, a test of multicollinearity using the variance inflation factor (VIF) indicated that all values of were less than the threshold VIF >10 [14]. Hence muticollinearity didn't exist.

TABLE I: REGRESSION ANALYSIS Coefficients $^{\mathrm{a}}$

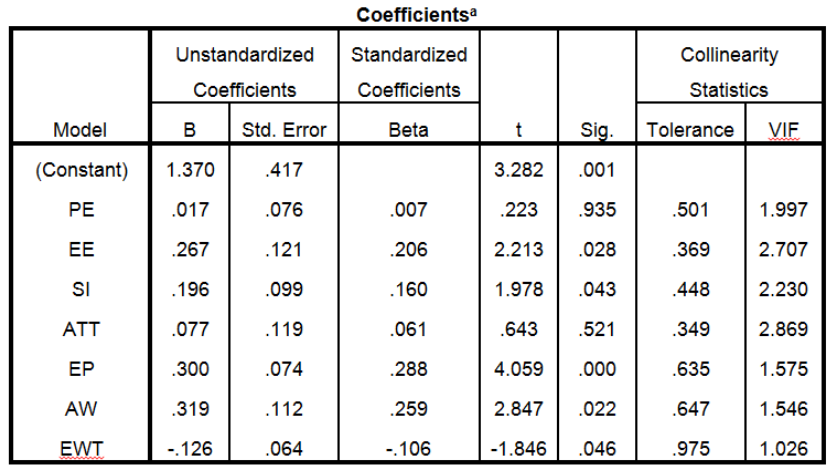

a. Dependent Variable: EregUsage

\section{B. Hypotheses Testing}

Hypotheses were tested using the results of the correlation and regression analysis. Results indicated that apart from $\mathrm{H} 2$ and $\mathrm{H} 7$ of the performance expectance and Attitude constructs respectively, the rest of the suggested hypotheses were accepted. Table of hypotheses testing has been left out due to space.

\section{DISCUSSION}

Results indicated that the influence of exerted pressure on the students' use of e-registration is high. Exerted pressure was also found to have a direct relationship with e-registration. These results are in agreement with what [12] noted that extreme time pressure has a constricting effect on an individual's decision making. This is because individuals under time pressure will concentrate on few salient indicators when making a decision by focusing on unfavourable information about the other available alternatives. More so, as [15] also noted, when perceived demands exceeds the perceived ability to cope with the demands, individuals tend to resist or absorb the pressure by succumbing to the factors that causes it. The implication of these findings is that those students who succumb to the pressure will use the e-registration whereas others resist. This explains the recurring strikes at the beginning of semesters.

Results also indicated that awareness is a crucial factor for the use of e-registration. The results of this study concur with the findings of [9] who highlighted the importance of trust on online system and suggested that before trust can be built, awareness has to come first. This implies that students need to have information about the e-registration system's, privacy, security and performance functionalities before they can build trust. The findings of this study also supports what [16] observed that, awareness reduces the fear of risks for online users and that lack of awareness may create continuous breakdowns in the knowledge flow and it impacts negatively on the system usage.

Social influence was also found to be significantly contributing to e-registration usage. Results support what previous researchers [1], [3] noted that peer influence is influential in the acceptance and use of the technology by students. This is true as in a university setting students tend to depend on others whom they; think are superior, see as a role model, stay and associated with. As [17] noted, much as perception of a system as easy to use depends on the technology, skills and experience of the user, explicit opinions obtained from others especially those an individual believe in will affect it. Students gain confidence when they are with one another.

In a university system, students may change their feelings and behaviors as a result of interaction with others they perceive to influence them like lecturers and friends. This may be caused by psychological principles such as balance, majority, or perception that lecturers are more academically experienced than them so they tend to behave so.

Effort expectancy was also found to be significant in the use of e-registration system. From the effort expectance point of view, it implies that when students are aware and effort is made to support their use of e-registration they will become comfortable with the system and then use it. This comfort may be achieved through training of students on how to use the system, establishing a help desk to assist those who are registering online or to improve on the system to have self-help functionality.

\section{A. Implications for Business}

This study provides a framework that could be leveraged by university's administrators to assess the factors necessary for e-registration. As [18] put it, administrator should not only concentrate on the technological competences of the system but also know the factors influencing those who use it. This will help organizations to create value from information technologies (IT) in which they invest huge sums of money. Hence, these findings will provide the university administrators with a wider basis for making better decisions 
amidst strict IT budgets.

This study also gives an insight on the ways to realize value from e-registration by giving the factors necessary for the students to use it. Therefore these findings could serve as useful guidelines for universities to develop their e-registration capabilities. More so since their demographic structures are exponentially increasing.

To more fully utilize the capacities of IT for effective development action, university administrators need to measure the appropriateness of IT like e-registration to certain organizational structures such as; number of students enrolled, number of staff serving them, number of campuses the university has, support departments and other departments that uses the data from students registration. In particular, those universities with big number of students and many campuses should pursue e-registration usage more seriously so as to leverage on the numerous benefits it provides.

The findings of this study shed light on the role of awareness for students' acceptance and use of e-registration. Hence, if universities are to leverage on e-registration benefits their marketing strategies need to be adjusted in order to include awareness campaigns, training programs and provision of help desks. The study also established that there is a positive correlation between exerted pressure and efficacy with web-based tools. This implies that if the university enforces mandatory usage of e-registration students will oblige to use it. Acceptance and usage of e-registration by students will enhance the university's performance. This is so because the different structures in the universities that depend on students' data to their work will be having the information as when they need it. This effective use of e-registration will help the university achieve the business value of IT, hence gaining competitive advantage.

\section{CONCLUSION AND RECOMMENDATIONS}

In this study, we presented a model for the acceptance and use of e-registration by university students. The study findings revealed that effort expectancy and social influence are mediated by efficacy to use web-based tools to influence actual e-registration usage. These findings are relatively consistent with other researchers [5], [7], [8]. The study also revealed that exerted pressure, awareness when mediated by efficacy to use technology influence actual usage. The developed model is expected to contribute to the literature in the research of students' acceptance and use of e-registration, practically it is also expected to act as a guideline for universities that are implementing on-line registration systems. By following the study's recommendation universities will be able to achieve business value from the IT systems in which they invest huge sums of money.

\section{A. Limitations and Recommendations}

This research was conducted basing on university of the Tshwane University of Technology (TUT) despite of the fact that students were sampled from four campuses. The sample used of TUT students only may not be a correct representative of all university students in South Africa. This is mainly because many students at TUT come from humble backgrounds and may not have been well exposed to IT like students in other universities who might have started using IT at high school.

It is also worth noting that the data in this study was collected at one single point in time where lecturers asked students to fill the questionnaires before or after the lecture. This might have a bias on results as when given a second-thinking students' answers may vary from those given in the prior collection. Furthermore, the analyses of the interacting effects of the students' demographics were not included in the final results to determine the change in the influence of the constructs with moderating effect. This might have caused unnecessary elimination of the construct which should have been significant after being moderated by the students' demographics. This study recommends that future research should take into consideration students' acceptance and use of e-registration based on their social and cultural backgrounds. This implies research should investigate technology comparison cross-culturally.

The moderating factors as already discussed should also be investigated in further research. It is essential to note that the framework of this study should further be validated with large data sampled from different institutions. The researchers also plan to use structural equation modelling for future validation to carry out the confirmatory factor analysis of the proposed model.

\section{REFERENCES}

[1] B. M. Kalema and R. M. Kekwaletswe, "Students acceptance and use of online registration systems in South African universities," presented at the Twelfth Annual Conference on World Wide Web Applications, Durban, SA, Sep. 21-23, 2010.

[2] C. Nanayakkara. (2007). A model of user acceptance of learning management systems: A study within tertiary institutions in New Zealand. Educause Australasia. [Online]. Available: http://www.caudit.edu.au/educauseaustralasia07/authors_papers/Nan ayakkara-361.pdf

[3] D. Jong and T. Wang, "Student acceptance of web-based learning system," in Proc. the 2009 International Symposium on Web Information Systems and Applications (WISA'09) Nanchang, P. R. China, May 22-24, 2009, Academy Publishers, pp. 533-536.

[4] W. H. DeLone, and E. R. McLean, "Information systems success revisited," in Proc. the $35^{\text {th }}$ Hawaii International Conference on System Sciences (HICSS 02), Big Island, Hawaii, 2002, pp. 238-249.

[5] V. Venkatesh, J. Y. L. Thong, and X. Xu, "Consumer acceptance and use of information technology: Extending the unified theory of acceptance and use of technology," MIS Quarterly, vol. 36, no. 1, pp. 157-178, 2012.

[6] M. H. Hsu and C. M. Chiu, "Predicting electronic service continuance with a decomposed theory of planned behavior," Behaviour \& Information Technology, vol. 23, no. 5, pp. 359-373, 2004.

[7] V. Venkatesh, M. G. Morris, B. G. Davis, and D. F. Davis, "User acceptance of information technology: Towards a unified view," MIS Quarterly, MIS Research Center, University of Minnesota, vol. 27, no. 3, pp. 425-478, 2003.

[8] P. Tibenderana, P. Ogao, J. Ikoja-Odongo, and J. Wokadala, "Measuring levels of end-users' acceptance and use of hybrid library services," International Journal of Education and Development using Information and Communication Technology, 2010, vol. 6, issue 2, pp. 33-54, 2010.

[9] S. Chandra, S. C. Srivastava, and Y.-L. Theng, "Evaluating the role of trust in consumer adoption of mobile payment systems," An Empirical Analysis Communications of the Association for Information Systems, vol. 27, pp. 561-588, 2010.

[10] J. L. Hale, B. J. Householder, and K. L. Greene, "The theory of reasoned action," in J. P. Dillard and M. Pfau, Eds., The Persuasion Handbook: Developments in Theory and Practice, pp. 259-286, Thousand Oaks, CA: Sage, 2003

[11] I. Ajzen, "The theory of planned behavior," Organizational Behavior and Human Decision Processes, vol. 50, pp. 179-211, 1991. 
[12] K. Krell, S. Matook, and F. Rohde, "The effects of regulatory pressure on information system adoption success: An institutional theory perspective," in Proc. the 17th European Conference on Information Systems, Verona, Italy, 2009.

[13] M. Robila, "Economic pressure and social exclusion in Europe," The Social Sci. Journal, vol. 43, pp. 85-97, 2006.

[14] J. Pallant, SPSS Survival Manual. A Step by Step Guide to Data Analysis Using SPSS for Windows, McGraw-Hill International, 2010.

[15] A. Whittle. (2007). What is psychological stress? [Online]. Available: http://ezinearticles.com/?What-Is-Psychological-Stress?\&id=512856

[16] D. Sharma, "Examining the influence of perceived risk on technology usage: Exploring the moderating role of trust," European Journal of Management, 2008.

[17] C. Hsu and J. C. Lin, "Acceptance of blog usage: The roles of technology acceptance, social influence and knowledge sharing motivation," Information \& Management, Science Direct, vol. 45 pp. 65-74, 2007.

[18] C. Buabeng-Andoh, "Factors influencing teachers' adoption and integration of information and communication technology into teaching: A review of the literature," International Journal of Education and Development Using Information and Communication Technology,(IJEDICT), vol. 8, issue 1, pp. 136-155, 2012.

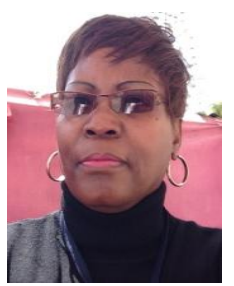

Mmamolefe R. Kgasi is a lecturer in the Departmen of End User Computing, Faculty of ICT, Tshwane University of Technology. Her research interests include application of computer systems in health care services, e-learning and emerging trends in technology.

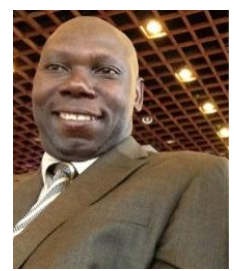

Billy Mathias Kalema holds a $\mathrm{PhD}$ in information systems, a master of science in computer science, a postgraduate diploma in computer science and a bachelor of science with education. He is a researcher, lecturer and mentor in the Department of Informatics, Faculty of ICT at Tshwane University of Technology. He has supervised several masters and doctoral studies in the field of information systems and has spoken in several international conferences, $\mathrm{PhD}$ symposiums, seminars and workshops. He is a member of the Institute of Electrical and Electronics Engineers (IEEE) and a senior member of the International Association of Computer Science and Information Technology (IACSIT). He serves on several technical committees as a peer reviewer for both journals and conference papers. Such as, the African Journal of Information Systems, International Journal of Innovation Management, Electronic Journal of e-Learning, Annual e-Leadership Conference and the Annual Conference on World Wide Web Applications.

Dr Kalema has published in several international peer reviewed journals and conferences. His is the author of the book 'critical factors influencing the use of ERP systems'. His research interests include enterprise resource planning systems (ERP), e-learning, ICT for education, research methodologies, individual's acceptance and use of technology and emerging trends in technology. His current and future research plans revolve around the practical application of research in daily life by putting IT to use especially in the economically and technologically disadvantaged developing countries. 